\title{
DISTANCE TEACHING AND PRESENCE TEACHING TOWARDS A POSSIBLE AND USEFUL INTEGRATION
}

\author{
Andrea Tarantino \\ University of Macerata, Department of Education, of Cultural Heritage and Tourism (Italy)
}

\begin{abstract}
The pandemic emergency seems to have extinguished many residual reservations regarding distance learning, but it has created a consensus that is all in all fragile, because it is non-critical and more charged with assimilative pressures.

The problem is not establishing when, where and whether distance learning or face-to-face training should be promoted. The problem is to understand why and to specify, jointly, with which paradigms it is necessary to operate. It is a question of tackling problems that have remained on the sidelines for too long, in order to understand what digital can offer to ordinary teaching and what from ordinary teaching can also be useful for distance teaching. We will stop on two issues only. On the one hand we will try to enhance the logic of the reticularity and composability of knowledge; on the other hand, we will focus on curricular systems, showing how each of these two aspects can benefit both distance and face-to-face teaching and, above all, how it can benefit their possible integration. And this also in order to be ready for the next emergency. Ready, while hoping it won't come.
\end{abstract}

Keywords: Didactics, new technologies, learning, curriculum.

\section{Introduction}

Never before has there been so much talk of presence and distance in the educational field.

And never before has the world known such a devastating pandemic as the one we are still struggling to face and for which it was necessary to make use of everything possible, including the potential offered by digital.

Thus, while the health emergency forced the isolation and reduction of physical contacts between people, with the help of technology we tried to mitigate the effects of distance in the workplace, leisure, sport, religion and therefore also in the world of education.

Presence and distance, however, are not only logistical options, because they have implications that must not escape those involved in training.

The fact that the world of schools and universities were not ready for this spatial displacement of teaching is understandable and this should make us reflect on the digital skills of teachers and on the use that is made of technology when used in presence.

Teachers who were forced by the pandemic to use technologies for the first time have usually relied on the procedural logic of every day, simply transferring online what they did in the classroom.

Re-proposing the same frontal model made up of lectures and interrogations, leaning on the technologies hastily put in place, certainly could not suggest a new teaching system.

Teaching always involves a sort of orchestration of several elements: organization of time and space, design of the environment (real and / or virtual), preparation of tools and methods ... and each of these elements interferes with everything else. You can't change an element and keep thinking as you did before. It would be an operation that is no longer sustainable.

The fact that today we prefer the mobile phone to the telegram or the e-mail to the letter entrusted to the post office does not only change the means of communication, but also the very meaning of communication.

So much so that today we are questioning - and not without good reasons - about the cognitive strategies of digital natives and their different "mental habitat" (Baricco, 2006).

Perhaps we are in the midst of a cultural phase of epochal transition that at least obliges us to a greater critical vigilance around the person's profile, his deepest needs, his way of dealing with dialogue with the group to which he belongs and so on, to discuss the skills and responsibilities of those involved 
in training or, more generally, of those who wonder about the different way of proposing themselves (and interacting) of the needs of the subjective and the social.

The theme of a possible integration between distance teaching and face-to-face teaching should also be placed in this broad framework, which in these pages we approach through two issues, starting from two apparently opposing perspectives, letting us be guided by a reflection on the possible enhancement of the network and composability of knowledge, on the one hand, and, on the other hand, due attention paid to curricular structures, showing that each of these two aspects can benefit both distance and face-to-face teaching and, above all, it can benefit their possible integration.

\section{Design}

\subsection{Knowledge reticularity} allows

Technology, by giving knowledge an increasingly clearly networked and distributed structure,

a) a greater attendance of potentialities in a certain sense forgotten by the mind set on linear rationality (think of abductive thinking, for example);

b) a different and richer approach to demonstration processes;

c) a new and poietic force to cognitive constructivism and therefore also to the processes of construction and use of knowledge, with very fruitful interferences for teaching / learning;

d) an unsuspected strong support for didactic criteria such as flexibility, individualization, social learning, experiential learning ...;

e) a fertile new recovery of theses, insights and proposals gathered from the history of pedagogy and from the history of teaching whose prophetic value is sometimes not understood.

Think, for example, of J. Dewey's discourse on experience, or even more remote researches such as those of Comenius, Pestalozzi, Decroly.

All this has required, requires and entails epistemological adjustments as well. Think, for example, of the revision of the concept of rule (now in fact replaced by the notion of regularity), of the idea of subsidiarity, of the concept of subordination ... And in any case it broadens the boundaries of educational responsibility, while opening new paths for construction of personal identity, for the consolidation of belonging, for the whole discourse concerning motivation and for the support to be ensured to divergent thinking and creativity.

These are perspectives, potentials, indeed, in many cases of authentic new resources conceptual, even before being instrumental - to be enjoyed with equal profit both in face-to-face teaching / learning paths and along multiple distance learning experiences.

The fundamental premise of learning is always and in any case a non-rigid structuring of knowledge, selected and processed, according to regularities that positively interfere with the subjective organization of knowledge no less than with the epistemic representation of disciplinary knowledge, as well as with motivational apparatuses.

Under these conditions we can also argue that teaching practices, designed for distance learning or even for face-to-face teaching "cannot start other than from the subject, from a careful reading of its reality and the need to be a protagonist in one's own knowledge and growth ". The student "cannot be the recipient of closed and purified designs, but the initiator and participant of desirable, modifiable, socially shared and dynamically lived proposals and projects" (Felisatti, 2007, p. 24).

\subsection{Curricular systems}

Similar difficulties are encountered if resources (conceptual and procedural) that are well present and active in face-to-face teaching are neglected. There are sensitivities, points of attention, hermeneutic constraints that cannot be lost only because we act online.

Sometimes school time appears constricting because it is homologated, little attentive to the diversity of learning styles and rhythms, that is, of individual differences and, consequently, of inclusive needs; but the time axis is always present. It is a question of understanding how it acts and how it can contribute to the good governance of the processes.

In the experiences conducted in the emergency phase, two different errors were made (and there is still the risk of them being made). Or the excess of confidence as if the transition to online can by itself remedy critical issues related to the structural structures of teaching; or - on the contrary - the renunciation of safeguarding structural nodes on which the whole teaching apparatus actually holds. In both cases the accused is the curricular system.

Apart, here, from a useful discussion of merit on the notion of curriculum and its many theoretical declinations (Paparella, 2009, v. II), we must take note of the centrality and unavoidability of a device - which we call the curricular model - which functions "as a hermeneutic structure and as a 
functional mediator to be used to interpret, understand, select, explain, choose, decide, compose, organize the entire range of issues concerning the aims, objectives and tools of didactic action in a coordinated manner and according to participation procedures "(Paparella, 2012, p. 169). Without support of this type, teaching is invaded by improvisation and is doomed to inconclusiveness.

That this organizational and hermeneutic support may then derive from thoughtful theoretical choices or from impromptu practical options is a matter that concerns professional ethics and the level of responsibility of the educational operator. The important thing is that at least the need is felt. And, in this case we must say that the experience of face-to-face teaching is certainly more attentive to this type of need.

What we hypothesize here is that even when a remote intervention is organized, curricular-type devices are put in hand.

In the most experienced experiences, the curriculum remains "implicit", and to some extent hidden in the folds of the operating rules of the so-called platforms.

What, instead, we hypothesize is that educators and trainers maintain a generalized habit with curricular devices, in every teaching situation, so that they can responsibly manage the functional link between objectives and purposes, between knowledge contents and experiential procedures, between learning and developmental needs.

Both in face-to-face teaching and in distance teaching, teaching is in fact called, as F. Frabboni said, to "put-in-communication the dimensions of development of the different generational ages (the cognitive and socio-affective" stages "of childhood, adolescence, youth ...) with the symbolic-cultural systems (the "structures" of the culture spread at school and in the after-school, as well as the ethical-social models of the community to which they belong): all within the multiple places of 'education, such as families, schools, associations, churches, the world of work, etc. " (Frabboni, 1998, p. 753).

\section{Possible integration}

In the moment in which shared dynamisms of functioning are identified, as - by way of example - we have found here in the reticular configuration and in the curricular structures, integration becomes possible.

It is no longer a question of juxtaposing, perhaps with a skillful dosage, assigning one hour to the other form of teaching (attendance and distance) according to this or that factor, but it is instead a question of vivifying one and the other with the same dynamisms. This allows those responsible for teaching to decide and choose without prejudice to common parameters and shared processes.

This is how legitimate interdependencies are established and correct principles of organization are maintained. This is how complexity can be governed, also being able to optimize relations and interpretation paradigms: "norming of behaviors, mapping of selections, construction and control of order" become possible objectives (Galliani, 1993, p.91).

\section{In the pandemic season}

If the pandemic has made the comparison with technology easier and more widespread and has made it somehow experiment the ways and potentialities of reticular knowledge, and if, at the same time, the widespread practice of the school with languages, operational styles and scientific literature flourished around the theme of the curricular system, it will be useful not to waste these resources and to work to bring them a system and to make them flow operationally both in distance teaching and in face-to-face teaching.

The path of integration is certainly richer than what is seen through these two functionalities (reticularity and curricularity); but their centrality with respect to the overall didactic structure makes us think that integration is possible. Above all, they make people believe that integration is extremely beneficial.

It makes you think that a new season is about to open, very promising and full of great promise.

\section{Conclusions}

We can say that the pandemic emergency has offered an opportunity for rethinking and reflection on the spaces and times of formation, spaces and times that are not only near and contingent, but also those not close, which open up to virtual horizons. 
This could be an opportunity for training to rethink old prejudices and try to better understand the potential of the virtual. After all, we are well convinced that it is precisely man to create his own world and then inhabit it, and then go even further towards a territory where subjective and objective meet where real and virtual confront each other and, together, open up the paths of innovation.

\section{References}

Baricco, A (2006) I barbari: Saggio sulla mutazione, Feltrinelli, Milano.

Dewey, J. (1949) Esperienza e educazione, Firenze, La Nuova Italia.

Felisatti E. (2007) La didattica come scienza, in Felisatti E., Rizzo, U. (a cura di), Progettare e condurre interventi didattici, Pensa Multimedia, Lecce.

Frabboni, F. (1998) Nel segno e nel nome della didattica. Problematicità e morfologia dell'ambito didattico, in "Studium Educationis", n. 4.

Galliani L (1993). Didattiche come organizzazione sistemica delle azioni formative, in Calonghi L. (a cura di), Il bosco di Chirone, Tecnodid, Roma 1993.

Paparella, P. (a cura di) (2009), Il progetto educativo. Vol. 2: Comunità educante, opzioni, curriculi e piani, Armando Editore, Roma.

Paparella, N. (2012). L'agire didattico, Guida, Napoli. 